\title{
Innovation for Inclusive Structural Change ${ }^{1}$
}

Tommaso Ciarli, SPRU, Science Policy Research Unit, University of Sussex, T.Ciarli@sussex.ac.uk

Corresponding author: Maria Savona, SPRU, Science Policy Research Unit, University of Sussex, M.Savona@sussex.ac.uk

Jodie Thorpe, Institute of Development Studies, J.Thorpe@ids.ac.uk

${ }^{1}$ An earlier and longer version of this chapter was presented as a report for the International Development Research Centre (IDRC), titled "Innovation Pathways to Inclusive Structural Change. A Framework for a New Research Agenda". This paper has received funding from the IDRC under the project "Pathways to Inclusive Development through Innovation, Technology and Structural Change”, co-led by SPRU and IDS at the University of Sussex. The paper has greatly benefitted from early discussions with Martin Bell and Raphie Kaplinsky, and from comments in the early stages of revisions by David O'Brian and Matthew Wallace and by participants in the workshops "Innovation pathways to inclusive structural change" in London (UK) and Nairobi (Kenya). We would like to acknowledge specific contributions by Jo Chataway, Xiaolan Fu, Fred Gault, Rebecca Hanlin, Richard Mavisi Liahona, Maureen Mackintosh, Dorothy McCormick, Smita Srinivas, and Anke Weisheit. We have also crucially benefited from constructive comments from the SWPS editors and one SWPS anonymous reviewer. Related articles are: Saha, A. and T. Ciarli. 2018. "Innovation, Structural Change and Inclusion: A Cross Country PVAR Analysis." SPRU working paper series, 1/2018. Brighton: Science Policy Research Unit. Saha, A., J. Thorpe, and S. Ayele. 2018. "Case Studies on Innovations in Breeding Practices in Kenya and Anti-retroviral Therapy Service Provision in Mozambique." IDS working paper, 505. Brighton: Institute of Development Studies. 


\begin{abstract}
The chapter proposes the foundations of an analytical framework to identify innovation pathways that lead to inclusive structural change in low- and mediumincome countries (LMICs). Innovation pathways depend on how actors, interactions, and conditions affect the origin of innovation; the uptake of the innovations (adoption and diffusion); the impact of this diffusion on upgrading; the extent to which technological upgrading scales up to drive structural change and inclusion; the complementarity among these processes; and the potential trade-offs between structural change and inclusion. After delineating the analytical framework, the chapter focuses on applications of the framework to identify typical trade-offs between inclusion and structural change, and policy options to tackle these trade-offs and achieve outcomes of inclusive structural change. We finally propose a research agenda to build upon the framework and directly inform policies for inclusive structural change. The contribution of this work aims to respond to the recently increasing demand coming from international institutions, inter-departmental research funds, NGOs and national ministries, for improved knowledge to shape a more effective innovation policy for inclusive development in LMICs.
\end{abstract}

Keywords: Inclusion; Innovation; Low and Medium Income Countries (LMICs); Technological Upgrading; Structural Change

JEL codes: O1; O13; O14; O33; Q13; I15. 


\section{Introduction}

There has been a rising interest in understanding how innovation can be steered to ensure more inclusion, condensed in the recent heightened regard to inclusive innovation policies, particularly within the context of the Sustainable Development Goals (SDGs) (Akhtar et al., 2018; Kaplinsky, 2018). ${ }^{2}$

The creation or adoption of new goods, services and processes can be destructive, in the Schumpeterian tradition (Schumpeter, 1934). The outcomes of innovation entail the creation of new activities and the obsolescence of existing ones, the need for new skills, leaving others to become redundant. New winners and losers are visible, as some segments of society benefit from their needs being satisfied, while others remain excluded. Also, when innovation is cumulative (Schumpeter, 1942), it may increase concentration at the expenses of smaller players (Autor et al., 2017), and often has consequences in terms of unequal income distribution (Aghion et al., 2015; Lee, 2011). Depending on who gains and who loses, innovation may therefore have inclusive or exclusionary outcomes.

At the same time, innovation may lead to more or less structural change at the national level, typically by increasing productivity across sectors, or increasing the share of employment in highly productive sectors. Structural change, in its own right, may also be exclusionary if, for instance, large parts of the population do not have the

\footnotetext{
${ }^{2}$ See for instance the UK research councils Global Challenges Research Fund (http://www.rcuk.ac.uk/funding/gcrf/) and work by the OECD (OECD, 2015; Paunov, 2013; Planes-Satorra and Paunov 2017) among others.
} 
skills to be employed in highly productive sectors, and remain un- or under-employed. If structural change and inclusion tend to be negatively associated in the short term, we will observe either innovation pathways of higher inclusion but lower structural change, or of more disruptive change that results in exclusionary outcomes.

The identification of the conditions under which innovation leads to both structural change and inclusion that reinforce each other in a virtuous circle of inclusive structural change (ISC), in the short and the long run, is therefore of high relevance for analysis and policy. Currently, the foundations of an analytical framework to unpack these conditions are not as developed as they could be, as the different bodies of literature on inclusion, innovation, and structural change have never been suitably bridged.

Our aim here is to propose the foundations of an analytical framework that unpacks the theoretical blocks behind innovation, structural change and inclusion, and supports testable hypotheses to understand how innovation leads to inclusive or exclusionary structural change in low- and medium-income countries. ${ }^{3}$

The framework has two main objectives: first, we provide a conceptual model to illustrate how the dynamics of innovation (INN), structural change (SC), and inclusion (INC) are interrelated, and we identify regularities behind pathways that combine different innovation, structural change, and inclusion outcomes; second, we propose a multidisciplinary, multi-methods research agenda to test several conditions

\footnotetext{
${ }^{3}$ The framework builds upon the large literature on the determinants of innovation. Therefore, our focus is not on how innovation occurs, but rather on the aftermath of innovation.
} 
leading to inclusive structural change. This agenda should better nourish industrial and development policy at large.

We first briefly map how innovation may impact on inclusion and structural change (Section 2). We then fully articulate the analytical framework and discuss possible pathways of innovation that might lead to different degrees of inclusive structural change. Here we unpack the potential virtuous or vicious dynamics between innovation (INN), structural change (SC) and inclusion (INC) based on the interactions between actors, processes and outcomes (Section 3). Third, we sketch how the framework supports the narrowing of some key gaps in the literature (Section

4), and how to incorporate policy lessons from the existing literature to highlight what would be needed to tackle various trade-offs and challenges (Section 5). We argue the case for policies to be framed under an overarching concern to achieve inclusive structural change. In Section 6 we summarize the key themes of this complex topic, and propose a research agenda to direct innovation toward inclusive structural change with the aim of responding to the recently increasing demand coming from international institutions, inter-departmental research funds, NGOs and national ministries, for better knowledge to shape a more effective innovation policy for inclusive development to meet the Sustainable Development Goals (SDGs) in LMICs.

\section{Innovation, Structural Changes and Inclusion: A First Glance}

Innovation induces structural change in economies and societies, and plays an important role in (economic) development (Cimoli and Dosi, 1995; Cimoli and Porcile, 2009; 2011; Hidalgo et al., 2007; Syrquin, 1988; Verspagen, 2004). As illustrated in Figure 2.1, both innovation and structural change might have inclusive or exclusionary outcomes. On the one hand, economic growth and structural change 
tend to reduce poverty (Ravallion and Chen, 2003), but the extent to which they do so depends on how income gains are distributed (Bourguignon, 2003). On the other hand, innovation might increase productivity and growth, but is often disruptive (Schumpeter, 1934), and may have distributional consequences (Aghion et al., 2019; Lee, 2011; OECD, 2015).

The extent to which innovation leads to more or less structural change and inclusion depends on several conditions (some of which can be measured), and the actors that enact and diffuse innovations, and how these actors interact. In Figure 2.1 the $x_{i}$ represent the conditions. These are capabilities, characteristics of the technology such as capital intensity and scale, sectors, final demand, geographical characteristics, and institutions. Beyond these conditions, the actors that are responsible for carrying out, channelling and adopting different forms of innovation and the way in which they interact, may also significantly influence the impact of innovation on structural change and inclusion. They do so not in a vacuum, but within a context affected by the conditions above $\left(x_{N}\right)$, which also determine the way in which they interact.

The literature envisages one of the two outcomes of innovation, as we discuss below: higher inclusion at the cost of lower structural change and potential for economic growth, or more disruptive changes that result in exclusionary outcomes. What are the conditions, actors and interactions under which innovation leads to both structural change and inclusion, and reinforce each other in a virtuous circle? For instance, by including more actors in the innovation process (Aghion et al., 2017; Bell et al., 2016), through greater access to technological capabilities, a country's opportunities to innovate may increase.

\section{[INSERT FIGURE 2.1 ABOUT HERE]}


We still have a limited understanding of which technological (and non-technological) innovations and in which context, lead to learning, technological upgrading, and further, to structural change (Cirera and Maloney, 2017). Also, the concept of inclusive innovation is still loose and the understanding of how it can be achieved is limited (Chataway et al., 2014; Cozzens and Sutz, 2014). There is limited evidence on which actors are included or excluded from innovation and development, and even less is known about the reverse dynamics, that is how inclusion and inequality influence successive phases of innovation and structural change.

The literature behind the blocks in Figure 2.1 has rarely been bridged under a single framework. However, doing so is necessary to identify the conditions $x_{n}$ that are relevant to explaining the effect of innovation on inclusion, structural change, and both (inclusive structural change), and to disentangle their effects on observable virtuous or vicious outcomes (the arrows in either direction). This chapter is a first step toward synthesizing the literature under a unifying framework.

\section{Inclusive Structural Change: The Analytical Framework}

We develop an analytical framework to understand how a number of conditions, actors, and interactions affect: (i) the diffusion of a given innovation in the economy; (ii) outcomes measuring structural change and inclusion; and (iii) their trade-off. The different outcomes are the results of different dynamic pathways. We envisage pathways that might lead mainly to exclusionary structural changes, mainly to inclusive outcomes yet with little structural change, or to inclusive structural change. We first define these elements before summarizing the macro relation between innovation, structural change, and inclusion as devised in our framework. 


\subsection{Building Blocks: Definitions and System Dynamics}

Innovation is defined as:

a new or improved product or process (or combination thereof) that differs significantly from the unit's previous products or processes and that has been made available to potential users (product) or brought into use by the unit (process) $\left(\mathrm{OECD/Eurostat,} \mathrm{2018,20).}{ }^{4}\right.$

The innovation could be new to the world, the market, or the producer. In our framework we do not assume that an innovation needs to be new to the world (highly radical), but to the local market and users (low degree of radicality or incremental). For simplicity, we initially ${ }^{5}$ assume that innovation occurs exogenously (technology transfer). The way in which innovation diffuses and generates structural change and/or inclusion depends on a number of conditions, actors and interactions, as shown Figure 2.1.

Conditions characterize the ways in which the innovation is absorbed into an economy (e.g. source, channels, characteristics of the adopters, technology), and its adoption and diffusion (e.g. demand, geography and capital intensity). The actors are individuals and organizations that are involved in any stage of the innovation process

\footnotetext{
${ }^{4}$ A major definitional difference introduced in the latest version of the Olso Manual is that innovation might occur in units other than business firms, including households or informal activities. This amendment might affect measurement of innovation most especially in LMICs, although we do not enter into this in more depth here. We do however include this in the research agenda on measurement.

${ }^{5}$ We relax this assumption when we look at the dynamic version of the framework.
} 
or in its diffusion/adoption. The interactions are the relations among the different actors, and may be market-related, social, and/or political.

We describe the flow from innovation to diffusion and to its outcomes in terms of structural change and inclusion as pathways, using the concept of pathways as defined by Leach et al. $(2007,18)$ as 'the particular directions in which interacting social, technological and environmental systems co-evolve over time'. Such a definition also embeds the circularity discussed below - changes in the outcomes (structural change and inclusion) at time $t$ influence innovation at time $t+1$. For the sake of readability, henceforth we refer to innovation as INN.

We define structural change as a shift of production toward assets based on higher knowledge and skilled labor, organization toward more efficient structures, exports toward knowledge intensive goods and services with high elasticities of demand, and the consumption of more luxury goods and services. These first order processes are accompanied by a number of outputs and outcomes. At the organization level these outputs and outcomes may include: increased technological capabilities and technological upgrading; upgrading in Global Value Chains (GVCs); and increases in the organization's average size and productivity, accompanied by more complex division of labor, and new occupational tasks and categories. At the meso level, technology is internalized, necessity entrepreneurship is replaced by opportunity entrepreneurship, informality reduces as a result of entrepreneurial opportunities, and activities agglomerate spatially. Institutions also evolve, become more complex, establish regulations on the labor markets, the environment, and technology (e.g. IPR), and the innovation system evolves. For readability, henceforth we refer to structural change as SC. 
Our definition of inclusion encompasses elements of relative pro-poor growth, and equity, beyond income inequality. We define inclusion as the result of a process to (re)-distribute benefits and losses, as well as power and decision-making, such that those who are currently marginalized acquire a prominent role in deciding about the pathways to follow and in turn reap net benefits from these changes. ${ }^{6}$ An innovation is considered to be inclusive when individuals who are currently excluded or marginalized from decision-making and the gains accrued to previous innovations are included in processes of economic development (as employees, producers, consumers), and their needs are explicitly addressed as a result. An innovation is also considered inclusive when individuals from excluded groups are involved in the processes through which innovation happens, such as the design and development of new goods and services. For readability, henceforth we refer to inclusion as INC.

We acknowledge that the relation between innovation, structural change, and inclusion is non-linear, and subject to a number of feedback mechanisms.

\footnotetext{
${ }^{6}$ Those who were excluded or marginalized from previous processes of economic development can be defined on the basis of income, or through discrimination against the social group to which they belong e.g. gender, ethnic or religious minority, migrant, or geographical.
} 
Figure 3.2 Innovation Pathways to Structural Change and Inclusion

Source: Authors' own elaboration 


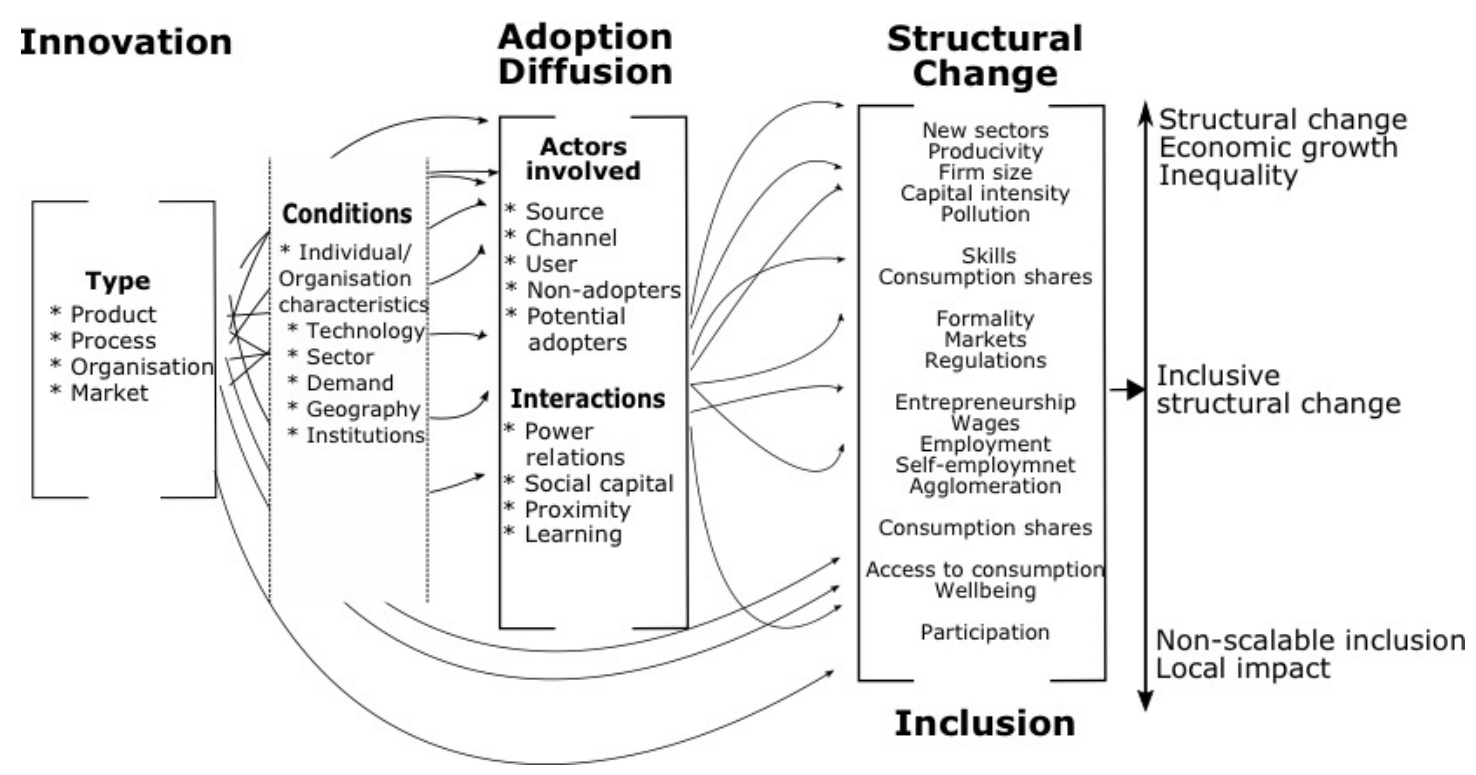

Notes: Arrows represent pathways. The variables that represent conditions, actors and interactions define the effect of innovation on adoption/diffusion, and on structural change and inclusion outcomes. Some pathways go through adoption/diffusion, while some variables have a direct impact on structural change and inclusion. Variables represent the innovation channels and sources, the type of innovation, as well as meso- and macro-conditions such as sectors, demand, geography, and institutions. In the extremes, innovation may have a positive effect on structural change, and a negative effect on inclusion (top end of the right axis), or no or negative effect on structural change and a positive effect on inclusion (bottom end of the left axis). The axis measures the trade-offs between structural change and inclusion outcomes. Structural change and inclusion are therefore not intended to represent different options - they are not mutually exclusive - but rather innovation processes may lead to different degrees of inclusive structural change.

.1 plots these relations in a system dynamics framework. In panel (a) we reproduce the same relations as in [INSERT FIGURE 2.1 ABOUT HERE]: innovation in time $t$ influences structural change and inclusion/exclusion in time $t+1$. In turn, outcomes of 
structural change may be (positively or negatively) related to inclusion. In panel (b) we plot the dynamic relations that include a feedback from structural change and inclusion in $t+1$ to innovation in $t+2$. Innovation (INN) is expected to have a positive effect on structural change (SC) (moving to more sophisticated products), which in turn is likely to generate more innovation. As a result, we obtain the reinforcing mechanism plot on the left-hand side. On the right-hand side, we plot the relation between innovation and inclusion/exclusion (INC/EXC). At the top right of Figure 3.1 innovation is assumed to be inclusive (INC). The inclusion of individuals and organizations in the innovation process may, for instance, lead to an increase in their capabilities, which also has a positive effect on further innovation or reducing capabilities by dispersing them. This may lead to a further reinforcing mechanism (top-right) or to a balancing one (where inclusion does not necessarily lead to learning and higher capabilities that facilitate future innovation). At the bottom-right part of Figure 3.1, innovation is assumed to be exclusionary (EXC). The exclusion of individuals and organizations from the innovative effort may have a negative effect on capabilities, reducing further innovation. This leads to a balancing mechanism (bottom right). However, exclusion may lead to increased capabilities of a limited part of the population, which may in turn increase innovation: in this case exclusion also leads to a reinforcing mechanism. Finally, structural change (SC) may also be inclusive (INC) or exclusionary (EXC). If inclusive, the positive effect of innovation on structural change further reinforces innovation through inclusion in the next time period. If exclusionary, the positive effect of innovation on structural change may reduce innovation in the next time period, depending on the effect of exclusion on capabilities.

[INSERT FIGURE 3.1 ABOUT HERE] 
We then face the following questions: under which conditions, forms of interactions and role of actors, does an innovation lead to (some form of) structural change and (some form of) inclusion/exclusion? Which aspects of structural change favour inclusion/exclusion? Which aspects of inclusion/exclusion favour structural change? To answer these questions, we remove the feedbacks (as in Figure 3.1 panel (a)). Questions about the reinforcing and balancing mechanisms (panel (b)) require replicating the framework for different phases of development, where each phase is shaped by previous outcomes in terms of structural change and inclusion: which aspects of structural change induce more innovation? Which aspects of inclusion and exclusion benefit or hinder further innovation? We will address these questions to some extent here, but leave their full conceptualization for future work, while we have attempted an empirical test of the dynamic pathways in a different work (see Saha and Ciarli, 2018).

\subsection{From Innovations to Structural Change and Inclusion: Illustrative Steps}

To answer the above questions, we map the steps through which several conditions, actors and interactions may affect the strength and direction of an innovation's impact on SC and INC (Figure 3.2).

First, an innovation is introduced, which may be indigenous (domestic or local), or adopted from somewhere else - leftmost column Innovation. The innovation may be of different types: product, process, organization, or market. Different local, national, and international actors may be sources and channels for the innovation, whose interactions may be differently shaped by power relations, governance, physical and social distances.

[INSERT FIGURE 3.2 ABOUT HERE] 
Second, the innovation becomes part of the system as soon as individuals or organizations adopt it, ${ }^{7}$ which may in turn lead to an upgrade of the product, the process, or the organization which produces/delivers it. It then diffuses as other actors in the system adopt it. The extent to which the innovation diffuses in the system also depends on a set of actors, interactions, and conditions, for instance, the capital intensity of the new technology, its scale, appropriability, adaptability, and cost. We distinguish between two types of variable: those that enable the access (or production) of the new technology; and those that act as an incentive to adopt. Examples of enabling variables are capabilities, access to resources, and other individual, organizational, institutional, and relational variables. Examples of incentive variables are the demand (domestic or international), scale, factor costs and other institutional variables (such as intellectual property rights).

Third, the diffusion of the innovation may cause different outcomes in terms of SC and INC, also depending on actors, interactions and conditions. Some of the actors, interactions and conditions have a direct effect on SC and INC outcomes, which are not conditional on the innovation's diffusion. For instance, negative environmental externalities are a characteristic of rapid structural change, particularly in respect to manufacturers. The negative externalities are likely to have a stronger effect on those parts of the population that are excluded for instance from the transformation from agriculture to a manufacturing economy, and the adoption of new production processes. The extent of both the SC and the negative INC depends on the diffusion of the innovation. The larger the diffusion of the polluting innovation, the larger the SC, and the stronger the adverse effect on those negatively impacted. In contrast, the

7 The first adopter may be the local innovator. 
participation in the innovation process does not depend on the diffusion of the innovation. In general, SC outcomes are related to diffusion and upgrading, and are therefore shaped by actors, interactions, and conditions that characterize adoption. For INC outcomes, the role of diffusion depends on the types of inclusion considered. Following the inclusion ladder (Heeks et al., 2014), inclusion outcomes at the bottom of the ladder (e.g. access to goods) are also shaped by actors, interactions, and conditions that characterize adoption. For inclusion outcomes at the top of the ladder (e.g. participation in the innovation process), the adoption of the innovation is not particularly relevant.

Fourth, structural changes and inclusion are not unrelated. Some SC outcomes are complementary to INC, but most tend to be incompatible (before redistributive policies, which consider only some aspects of inclusion). For instance, an innovation may decrease the price of a good that was previously only affordable to a limited part of the population, increasing its access (e.g. milk in Kenya) (Saha et al., 2018). As a result, we observe an increase in the product's share of total household consumption, and an increased share in consumption of that good in relation to others in its category. While this is compatible with increased inclusion (measured as access to goods), in the short term an increase in the capital intensity of production will not result in increased employment: only the most skilled workers have access to the available jobs, excluding a large part of the unskilled population. 


\section{Inclusive Structural Change: Bridging the Gaps in the Literature}

\subsection{Technological Upgrading, Structural Change, and Inclusion: A Brief Synopsis of the Existing Literature}

There is limited literature that looks at the relationship between innovation/technological upgrading, structural change and inclusion - let alone the three-way link under analysis here.

A first immediate channel that leads from technological upgrading to structural change is through the mediated effect on productivity. Dense interactions in the adoption of innovative technologies help to close the productivity gap between pioneering firms, early adopters and late adopters, which is essential to raising productivity levels across the economy, and generating structural change (Lundvall, 2007). Where exposed to competition, domestic firms are pushed toward more efficient practice and to increase capabilities, and productivity growth in existing sectors and employment shifts toward more productive sectors (McMillan et al., 2014).

However, economic upgrading following structural change does not necessarily generate social upgrading (i.e. access to better work opportunities, including measurable standards, wages and conditions, and enabling rights such as freedom of association and non-discrimination). For instance, the position of firms and workers within the value chain, the type of work performed, and the status of workers within a given category of work will influence the capacity to achieve inclusion and social upgrading through structural change (Barrientos et al., 2011; 2016a; 2016b; Bernhardt and Pollack, 2016; Brewer, 2011; Lee and Gereffi, 2015; Milberg and Winkler, 2011; Tokatli, 2013). 
At the micro-level of analysis, inclusion might result from technology transfer and technological upgrading, depending on a set of further conditions and contextual characteristics. The literature has identified these as the appropriateness of technology (Kaplinsky, 2011; Hanlin and Kaplinsky, 2016); measurable standards and enabling rights (Barrientos et al., 2011; 2016a; 2016b; Bernhardt and Pollack, 2016; Brewer, 2011; Lee and Gereffi, 2015; Milberg and Winkler, 2011; Tokatli, 2013); user involvement (Foster and Heeks, 2013; Kaplinsky, 2011; Zeschky et al., 2011) and institutional inclusiveness (Acemoglu and Robinson, 2012; Acemoglu et al., 2005; Altenburg, 2009; Farole et al., 2011). ${ }^{8}$ The mechanisms that affect inclusive outcomes of innovation are even less explored.

Paunov (2013) suggests that innovation affects inequality in three ways: first, through direct impact on income distribution (e.g. innovation favours the highly skilled and risk takers); second, by offering solutions for improving the welfare of lower and middle-income groups (frugal innovators); and third, by allowing lower-income groups to innovate themselves, with an ambition of greater welfare improvement (i.e. grassroots and informal-sector activities).

The literature has also highlighted that labor-intensive, cheaper and low-quality intermediate outputs and technologies produced and used by firms in Southern countries are more appropriate for firms in other countries in the South. ${ }^{9}$ For similar

\footnotetext{
${ }^{8}$ An exhaustive map of the literature dealing with the role of International Technology Transfer as a specific source of technological upgrading at the micro, meso and macro levels is offered in Marquez et al. (2017).

${ }^{9}$ See Section 5.1 for a review of the South-South trade and its role in achieving inclusive structural change.
} 
reasons, these innovations are more accessible for SMEs and for disadvantaged groups, such as women (Hanlin and Kaplisnky, 2016).

On the distribution of the returns to innovations, and how the initial income distribution influences innovation, a recent scholarship has studied how market and technological innovation might usefully create new opportunities to include poor and marginalized people from low-income countries in the global economy (Chataway et al., 2014; Heeks et al., 2014).

At the meso-level of analysis, scenarios of growth and structural change still entail a substantial heterogeneity in terms of inclusiveness and inequality, depending, amongst other things, on the institutional configuration of nation states. Acemoglu and Robinson (2012) distinguish between inclusive institutions, which promote learning and shared prosperity, and extractive institutions, designed to extract resources from society to benefit elites (see also Altenburg 2009; Farole et al., 2011; Hickey et al., 2014; Papaioannou, 2014; Rodrik, 2005; Teichman, 2016).

At the macro-level of analysis, the relation between structural change that fosters economic development and inclusion has largely been framed within the issue of how to achieve pro-poor growth, (Anand et al., 2013; Atkinson and Bourguignon, 1999): the rate at which the income of the poor rises for a given increase in national income (absolute), or with respect to the growth of the rest of the population (relative). According to Ravallion and Chen (2003), growth is distribution-neutral, and always has a positive impact on the poor, raising their income. Early stages of economic development, though, are often accompanied by changes in income distribution (Kuznets, 1973; Ravallion, 2004), which follow the economic transformation. Poverty reduction eventually is a combination of income growth, changed income distribution, 
and the relation between income growth and its distribution (Bourguignon, 2003). Some authors would argue that economic growth is always inclusive because of its effects on poverty reduction, but the degree of inclusiveness (how much poverty is reduced, if we use poverty reduction as a macro indicator of inclusion) depends on how equitably the increased income is distributed.

Since income inequality (one of the macro indicators of inclusion) may directly affect economic growth, economists have attempted to explain the negative effect of inequality on economic development as an outcome of political economy (Acemoglu et al., 2005; Alesina and Perotti, 1996), capital, insurance and/or labor market imperfections (Banerjee and Newman, 1993), commons, and conflict (Esteban and Ray, 2011). Lower levels of inequality measured as equal access to productive assets, economic opportunity, and voice, are claimed to have a positive effect on economic development (World Bank, 2006). However, a wealth of empirical tests has not provided conclusive evidence on whether economic development leads to more inequality, at which stage of economic development, and even less on whether lower inequality leads to more or less economic growth.

Overall, it seems there is a long way to go in terms of further empirical research to disentangle the three-ways link between innovation, structural change and inclusion as we put it forward in the analytical framework in Section 3. We reprise the issue and propose avenues of exploration below and in the subsequent Section 5.

\subsection{Innovation for Inclusive Structural Change: Narrowing the Gaps}

To summarize the key messages of our argument so far: structural change is a foundational component of economic development, which is in general, poverty reducing. However, these processes may be relatively inclusive or exclusionary, 
depending on the initial income distribution and on whether there are sustainable opportunities created for the poorest.

Innovation and the accumulation of technological capabilities effect the extent to which structural change can be inclusive or exclusionary; however, the bulk of the literature mainly covers the emerging (rather than low-income) countries, the manufacturing sectors, and a few successful firms or clusters of small firms. The analytical framework proposed in Section 3 allows us to better identify the gaps in the literature that would need further research effort to be pursued.

First, we know little about which innovations, in which contexts, lead to learning, technological upgrading, and further to structural change. It has been argued that innovation more conducive of learning might not necessarily be the most radical, but rather incremental (Bell, 2009). The latent bias toward radical, more disruptive innovations therefore might be comparatively less inclusive or learning-conducive.

Second, the understanding of the relationship between innovation and inclusion has gained from conceptual developments and definitions of inclusiveness, but the concept of inclusive innovation is still quite fuzzy and the understanding of how it can be achieved is limited (Chataway et al., 2014; Cozzens and Sutz, 2014). There is also limited empirical evidence on who is included/excluded from a specific innovation and development process.

Third, the understanding of how inclusion and inequality influence successive phases of innovation and structural change is even less developed. Also, the evidence on the effect of inclusion on structural change is far from conclusive. This relation is based on rather aggregate measures of inclusion, such as poverty and inequality, with little attention to exclusions based on ethnicity, geography, gender, and other non- 
economic dimensions. Most fundamentally, exclusion might occur at the level of access to information in regard to decision-making in investments and participation in the decision-making process. We also know little about the direction of structural change, which is likely to depend on which innovations endure or dominate and which are replaced and disappear.

By proposing an analytical framework that accounts for all of these aspects and the dynamics within them, our ambition is to direct empirical research toward addressing the gaps identified above. Going beyond a macro-economic accounting perspective, our framework should be exhaustive enough to allow for the investigation of how the main driver of growth (innovation) influences the transformation that accompanies growth (structural change), the (re)-distribution of the gains from innovation (inclusion/exclusion), and how the three dynamics are influenced by different conditions, actors, and their interactions.

In addition, we are aware that, in addressing the gaps above, it is important to build upon and go beyond the stylized dynamic relationships between innovation, structural change and inclusion that have served the purpose of founding this framework. It is important to consider the trade-offs (and bottlenecks) that effect each link at each stage, and how these might be addressed through policy. We address this in the next section.

\section{Inclusive Structural Change: Three Cases of Trade-offs in LMICs and the}

\section{Role of Policy}

Trade, investment, innovation and diffusion proceed via the decisions and interactions of numerous public and private actors - artisans, civil servants, community workers, consumers, employees, entrepreneurs, farmers, and ministers, among others (Figure 
3.2). These decisions together shape outcomes in terms of structural change and inclusion, and the trade-offs between them. While actors' decisions reflect their priorities and interests, they are also shaped by a series of policies, regulations, and incentive structures which influence these priorities and interests.

On the one hand, technological upgrading may promote structural change with inequitable patterns of winners, who reap the lion's share of rewards, and losers, who are left behind or carry a disproportionate share of the costs. Policies are needed to balance these trade-offs by changing or enabling new incentives and practices, and result in a different and more equitable distribution of costs and benefits. On the other hand, innovation may take place in ways which are highly inclusive of currently marginalized groups, ensuring their participation in both the process of innovation and its outcomes, but with few structural effects. The role of policy can then be to enable access to the resources necessary to scale up structural change from these more inclusive processes.

This section reviews literature with respect to innovation, trade and related policies, and their role in managing the trade-offs between inclusion and structural change, particularly in low-income countries. It considers three settings that may be more conducive of learning and capabilities accumulation than North-South transfer of more radical, disruptive innovation. These are (1) South-South trade and investment, (2) agglomeration economies that facilitate technology diffusion, and (3) indigenous grassroots innovation. It offers policy considerations for each setting: in which ways may public policy move outcomes toward the centre of the structural changeinclusion spectrum (Figure 3.2), based on the state of current knowledge? 


\subsection{South-South Trade and Investment}

Low-income economies tend to be characterized by two disparate groups of firms with very different levels of assets. The majority are low-productivity small or micro firms, often in the informal sector. These firms predominately operate in isolation from a much smaller group of large and more productive firms, including subsidiaries of foreign corporations (Altenburg, 2009). Unlike in high-income countries, there is relatively limited productivity growth of firms in the first group, even those in the formal sector. While technology upgrading by these small firms does create needed jobs and contributes to productivity growth, structural change is largely determined by the larger and more productive firms (Van Biesebroeck, 2005). These large firms are in a position to attract higher productivity labor, have better access to capital and greater capacity to adopt new technologies. While the productivity increases by these firms support structural change, the outcomes are likely to exacerbate exclusion, at least in the short term.

Given that technology upgrading in low-income countries relies predominately on the diffusion of new-to-market technologies, rather than new-to-world innovation (Bell, 2007), global value chains are a route to technological upgrading and higher value adding activities (Fu et al., 2018; Jaffee and Masakure, 2005; Pietrobelli and Rabelloti, 2006). Which firms participate in global value chains, and how valueadding activities are distributed are frequently determined by the dominant or lead firm in the chain (Kaplinksy, 2000; Ponte and Gibbon, 2005).

Small and informal producers are generally excluded from Northern-firm-led value chains - unable to meet exacting standards, and hampered by low productivity and poor quality infrastructure which undermine their competitiveness (Dolan and 
Humphrey, 2000; Maertens and Swinnen, 2009; Poulton et al., 2008). On the other hand, where the lead firms are located in the South, there is greater likelihood of knowledge transfer and skills upgrading that enables firms to move up the chain into higher-value activities based on technology more similar to their own (Gold et al., 2017; Mohanty et al., 2019). A smaller technology gap within this network also enables technological diffusion via learning-by-doing, supporting diversification in manufacturing exports by local firms (Amighini and Sanfilippo, 2014; Didier, 2017).

Technology diffusion also depends on the human and financial resources and the absorptive capacity of firms (Cohen and Levinthal, 1989; Keller, 1996; Zanello et al., 2016). More advanced technologies from developed countries are more likely to be adopted by firms in the already productive group, which have the necessary resources and absorptive capacity to take up the technologies. Since these recipients of NorthSouth technology transfer achieve higher productivity growth (Gold et al., 2017), the result is likely to be structural change without inclusion, as already larger and more productive firms pull further away from the rest. These exclusionary outcomes may be counter-balanced where they support employment growth; however, the evidence on the relationship between North-South vs South-South trade and employment is mixed (Gold et al., 2017; Mohanty et al., 2019).

The extent and type of trade and investment patterns are influenced by policy factors, including trade policy itself. Currently, although trade liberalization has led to an overall reduction in trade tariffs imposed by Southern governments, tariffs imposed on imports from other LMICs tend to be higher than for imports from developed countries (Jha and McCawley, 2011). Policy in sectors that support trade is also relevant. For example, poor trade-related infrastructure and logistics, or infrastructure directed at supporting trade with countries in the North, rather than with other LMICs, 
undermines South-South trade (Jha and McCawley, 2011). Another area is finance. Greater financial sector development in LMICs supports trade in technology and skillintensive manufactures, and the effect is highly significant with respect to SouthSouth trade (Demir and Dahi, 2011).

Policies that support inclusive structural change will therefore address these tradeoffs. One approach is to support structural change through North-South trade while introducing policies that enable those left behind to cope with or benefit from these changes, such as through social protection or significant public investment in human capacity development (Timmer, 2009). Alternatively, trade policies may be geared toward (more inclusive) South-South trade, but coupled with efforts to build the capacity of small firms and their access to finance, contributing to greater productivity gains and growth (Mohanty et al., 2019). Of course, policies may also seek to strike a balance between these two alternatives.

\subsection{Agglomeration Economies and Diffusion}

Agglomerations and networks of enterprises and other economic actors, such as those found in industrial clusters and in cities, enable knowledge exchange and joint learning at relatively low cost. Outcomes may include technology adaptation and diffusion, and increased productivity supportive of structural change - although these outcomes are not guaranteed (Wolman and Hincapie, 2014). The contribution of clusters and cities to inclusive structural change depends on who has access to these spaces and networks, and the degree to which supply and demand side constraints to wide-scale productivity growth are addressed. 
Clusters facilitate innovation through knowledge diffusion and spillovers, including the exchange of tacit knowledge, which is otherwise difficult to codify and transmit (Cumbers and MacKinnon 2004). Clusters are also distinguished by joint actions by the firms which comprise them, leading to greater collective efficiency (Schmitz 1999). Through encouraging the development of more specialized suppliers and creating demand for labor with specialized skills, clusters increase productivity (Porter 1998; Wolman and Hincapie 2014).

For LMICs, clusters enable small firms to achieve upgrading without having to invest across the entire production process. Instead they can concentrate on taking much smaller risks in particular steps of the process, while other enterprises in the cluster invest in complementary tasks (Schmitz, 1999). As a result, there is often an uncharacteristically high proportion of medium-sized firms represented in clusters in LMICs, although again this outcome is by no means guaranteed (Ibid).

While clusters have mostly been studied in relation to industrial sectors, and to a lesser extent business services (Di Meglio et al., 2018; Meliciani and Savona, 2015), clustering can also be applied to the promotion of agriculture (Galvez-Nogales, 2010); highly relevant for LMICs. Agricultural clusters are based on the coordination of smallholders and agribusinesses to benefit from increased opportunities, reduced costs and spillover effects.

Urbanization is another process of agglomeration taking place in LMICs, pulling people, enterprises and resources into closer proximity, and, as for clusters, enabling valuable informal learning and the accumulation of knowledge. Cities allow for the sharing of infrastructure and distribution of risks, while improving the quality of matches between actors in the value chain, or between enterprises and employees with 
appropriate skills and knowledge (Duranton and Puga, 2004). Cities thus offer knowledge, skills and other resources, which enable innovation and upgrading, as well as a high density of demand (Srinivas, 2014). This in turn creates a strong pull factor.

Despite obvious benefits, the distributional outcomes of these agglomerations are unlikely to be neutral. The fact that clusters support the free spread of ideas among smaller firms and informal enterprises (Kraemer-Mbula and Wunsch-Vincent, 2016) means that they may enable more inclusive forms of innovation. On the other hand, clusters are not only spatial mechanisms but have a network aspect reliant on social capital, interpersonal relationships and trust. As a result, clusters may exclude or further isolate firms led by those who are socially marginalized, based on ethnicity, religion or gender, for example.

The benefits of agglomeration are also in tension with its burdens, such as increased urban crime, pollution and crowding (Scott and Storper, 2015; Storper and Scott, 2016). These burdens adversely affect those who are negatively included in them. The key question is how the benefits and burdens of agglomeration are accrued or borne by different actors.

While the processes of coming together into clusters or cities often takes place spontaneously, driven by market and other forces, they may also be shaped by policy (Galvez-Nogales, 2010; Wolman and Hincapie, 2014). For example, people and enterprises may occupy different urban locations as a result of market forces e.g. based on the price of land; or due to the actions of government authorities e.g. through the provision (or not) of infrastructure and facilities (McGranahan et al., 2017). 
Policies promote clusters where they address weak elements of the ecosystem by making land or transportation more available, offering relevant skills development programs, facilitating horizontal or vertical coordination, encouraging knowledge spillovers or networking, and fostering the growth of intermediary institutions and supporting services (Martin and Sunley, 2003; Wolman and Hincapie, 2014).

However, there is little evidence of governments successfully creating entirely new industrial clusters in particular places (Wolman and Hincapie, 2014). Moreover, subsidies that encourage, or regulations that restrict, investment in certain geographies can intentionally or unwittingly support or undermine cluster formation (Porter, 1998).

Local authorities and urban planning policies may also intentionally (to discourage further migration) or inadvertently exclude low-income residents and low-skill migrants from the benefits of agglomeration economies by confining them to certain areas of the city or denying them access to secure employment or basic services. However, where formal authorities recognize the legitimacy of these groups and their needs and capacities, policy may be formulated in ways that support their inclusion, while also contributing to greater effective demand. Urban planning and policy is also important in managing the production and distribution of negative externalities (Scott and Storper, 2015).

\subsection{Indigenous and Informal Sector Innovation}

Trade and investment from both North and South offer sources of new-to-market technologies in low-income countries, supporting varying degrees of structural change and inclusion (as described above). Indigenous innovation involving technology adaptation in the informal sector of low-income countries offers an alternative 
pathway. It centers on incremental, learning-based innovations by firms with relatively low capabilities and minimal capital resources which adopt, adapt and improve technologies. They may do so in response to specific constraints (Fu et al., 2018; Robson et al., 2009); or slight variations in the local market (McGranahan et al., 2017).

Closely related to the concept of informal sector innovation is that of grassroots innovation (Fressoli et al., 2014; Smith et al., 2014). Grassroots innovation refers to bottom-up efforts arising from communities and users who are directly involved in the process and/or outcomes of innovation. These are more deliberate and values-based alternative pathways of inclusive innovation and development. The focus is also on empowerment, such that groups achieve greater voice and control over their futures (Arza and van Zwanenberg, 2014; Fressoli et al., 2014).

Indigenous informal sector and grassroots innovation supports inclusivity since groups that are normally marginalized move to the center of the processes of innovation and the benefits arising from them, as they meet local needs. Indigenous innovation in informal firms in LMICs has also been shown to increase labor productivity, and improve these firms' performance (Agyapong et al., 2017; Fu et al., 2018). There is nevertheless a wide gap between these locally-developed solutions and achieving the wide-scale productivity growth necessary for structural change.

Time and financial resource constraints constrain the forms of innovation possible (Kraemer-Mbula and Wunsch-Vincent, 2016). Innovators that invest in new activities and new knowledge assets also lack any guarantee of their ability to appropriate the benefits (Hausmann and Rodrik, 2003), acting as a further deterrent. Low population density (especially in remote rural areas) and/or weak spending power contribute to 
low effective demand, limiting the scale and reach of informal firms in localities with these characteristics.

There is little systemic policy guidance on innovation in the informal sector. Although attitudes are beginning to change, policymakers have often been blind to such processes, with policies that are geared toward suppressing informality rather than being supportive so as to enable innovation within it.

That said, enabling policies for informal innovation might include those that address general limiting factors, such poor quality infrastructure, informational constraints, a lack of skilled labor, poor access to finance and the weak skills of entrepreneurs (Bradley et al., 2012; Kraemer-Mbula and Wunsch-Vincent, 2016). More innovationspecific measures would overcome initial barriers for innovators, for example by reducing regulations or requirements, providing low cost credit or other subsidies, enabling linkages between informal and formal firms, or enabling entrepreneurs of high ability to migrate to the formal sector (Fu et al., 2018; Hausmann and Rodrik, 2003; Kraemer-Mbula and Wunsch-Vincent, 2016). These policies would ideally be matched by mechanisms that enable effective demand, for example by addressing distributional and delivery problems, overcoming informational problems, and raising incomes through wage policies or welfare regimes (Srinivas, 2014). Policies that better enable networking, with support from intermediaries, can also be important to the diffusion of grassroots innovations (Hossain, 2016). 


\section{Conclusions: A Research Agenda on Inclusive Structural Change}

\subsection{Summary of Key Themes}

The chapter proposes a novel framework, which provides the analytical foundation of the concept of inclusive structural change, in order to inform future empirical research and policymaking. From the conceptual advance of this new framework, we seek to understand the dynamic relationship between innovation/technological upgrading, structural change and inclusion.

The main conceptual building blocks of our framework are set out in Sections 2 and 3. Our ambition is to identify and systematize the main actors involved in these processes; the way they interact in processes of technology transfer, capability building, innovation diffusion and delivering (virtuous or vicious) outcomes in terms of structural change, inclusion and economic/social sustainability. Our overarching aim was to achieve generalizable knowledge that would help understanding these processes in different low- and middle-income contexts. Ultimately, we have aimed to respond to the recently increasing demand coming from international institutions, inter-departmental research funds, NGOs and national ministries, for better knowledge to shape more effective innovation policy for sustainable and inclusive development in low-income countries.

Our analytical framework can be illustrated through the following narrative. A number of interacting actors (entrepreneurs, households, local communities, local government, managers, national ministries and workers) are responsible for carrying out, channelling and adopting different forms of innovation. They do so not in a vacuum, but within a context affected by a number of variables. The creation of new goods and services by means of new processes and organizations is by all means a 
destructive phenomenon, in the best of the Schumpeterian tradition. The outcomes of these processes entail the creation of new activities and the obsolescence of existing ones; the need for new skills and others to become redundant or no longer; segments of the society benefiting as a number of their needs are newly satisfied, while others remain excluded. Structural change and inclusion might therefore reinforce each other in a virtuous circle; or rather be conducive of pathways of higher inclusion but lower structural change or of more disruptive change that results in exclusive outcomes.

As mentioned, our ambition is that the conceptual categories of our framework and the novel way of systematizing the actors, interactions and outcomes of relevant processes, will be used to test specific applications of it. For instance, technology upgrading leading to structural change depends fundamentally on existing local capabilities, absorptive capacity, the ability to upgrade capabilities, production and innovation capabilities, consumer preferences and needs, and not least on the ways in which the public sector and public research interact with the private sector within a context of aligned incentives. However, the gaps in the literature needed to be addressed and bridged, remain substantial.

We have in fact highlighted that the mechanisms that regulate inclusive outcomes of technological upgrading and structural change are comparatively less explored. These mechanisms are affected by a number of conditions, which are usually considered in the realm of the inclusion literature, yet they seem to be disconnected from the one on technology transfer. Our effort has allowed the identification of some mechanisms, such as the appropriateness of technology; the role of measurable standards and enabling rights; the degree of user involvement; and finally, institutional inclusiveness. However, much work remains to be done. 
We have devoted particular attention to highlight the trade-offs between innovation, structural change and inclusion, that ideally could be counterbalanced by policy action. We have reprised these themes in the case of South-South trade and investments, that have delineated some policy options to address the trade-offs between inclusion and scalability of the structural change that might result from these activities. Other cases of trade-offs between innovation, structural change and inclusion can be found in the recent enthusiasm for grassroots innovation in LMICs. This, inclusive almost by definition, could be adequately supported by policies that point to a higher scalability. Similarly, we have looked at trade-offs in innovation and inclusion in specific spatial organizations such as clusters and cities in LMICs. Enabling clustering, networks and agglomeration economies in LMICs, in ways that include rather than exclude, would represent a particularly effective policy aim; one that build up trust and social connectivity, and at the same time facilitates learning and knowledge spill overs.

\subsection{A Research Agenda toward a New Political Economy of Inclusive Structural Change}

Our novel analytical framework has allowed the identification of a number of research gaps that we consider particularly useful to systematize in the context of this chapter.

In order to develop a thorough understanding of the positive and normative elements of inclusive structural change, a substantial effort should be devoted to test the analytical framework with further, more systematic quantitative and qualitative evidence. Also, most importantly, more extensive reflections on the political economy of these processes, expressed through the integration of innovation, industrial and trade policy in order to align objectives that might currently be at odds with each 
other, is of fundamental importance. Often the policy implications around innovation are targeted to contexts that are at best middle-income countries, whereas acting in LMICs represents an obviously different challenge. Generating an integrated platform of evidence to inform development policy in LMICs is therefore the core ambition of this research agenda.

A number of policy implications emerge, relevant to the topic outlined. These are both based on the policy options proposed in Section 5 to address the specific cases of trade-offs between innovation, structural change and inclusion, and informed through extensive discussions with stakeholders, academics and policymakers that have received and discussed our results, and presented their own views and priorities. The implications thus identified, highlight areas that need much further development, both at analytical and, mostly, at empirical (quantitative and qualitative) levels, if we are to strengthen policy and improve theory toward a new political economy of inclusive structural change.

\subsubsection{Innovation and Technology Transfer for Inclusive Structural Change}

We can imagine the innovation space as a continuum that has at one extreme formal R\&D and traditional old generation technology transfer, and at the other, indigenous, informal and possibly grassroots innovation. Two main issues emerge: (i) R\&D might not be as important as one might expect from theory, as it might not effect - in the short term - the capacity to generate change autonomously in local contexts; (ii) traditional channels of technology transfer, such as trade, FDI and GVCs, might not be as important as they have been in developed economies, due to issues of governance and specialization lock-in; (iii) however, much of the grassroots, local and 
informal innovations that might be inclusive locally, are likely to lack sufficient scale to ensure sustainable growth enhancing structural change, as illustrated above.

In this context, it is of crucial importance to start off with a process of local and endogenous change by ensuring scalability, and persistent change. If so, regional and local embeddedness should be prioritized over entering - for instance - GVCs prematurely (Lopez Gonzalez et al., 2019). In the context of inclusive structural change in LMICs, this calls for a thorough revision of the potential roles of trade, industrial policy and innovation policy and most importantly their integration in a coherent platform of instruments. The case of favoring South-South trade illustrated earlier, is an exemplative case in this context.

\subsubsection{Challenges for Innovation and Industrial Policies}

The roles of industrial and innovation policy in these contexts should therefore be, first and foremost, to identify relevant opportunities for indigenous innovation and secondly to make sure that indigenous innovation is scalable and made endogenous to change. In this respect, several challenges have been identified.

First of all, the traditional technology transfer and innovation system narrative should be complemented with a careful consideration of the political economy of the whole process. Potential solutions that support a move in this direction entail either feeding innovation incentives into existing market incentives that are beneficial to inclusion and at the same time to fight perverse incentives or, alternatively, create these virtuous (innovation + inclusion) market incentives from scratch. In this respect, the question is how to align incentives of actors as diverse as entrepreneurs, consumers, donors and policymakers, communities, private sector and multinationals. The notion of an entrepreneurial state applied to LMICs is attractive but poorly equipped to 
account for the complexity of the necessary incentives. At the early stages of the creation of necessary conditions for these incentives to be aligned, it would be rather more important to make actors work collectively and with iterative measures to support incentive alignment, which is of paramount importance for development.

A second overarching element that emerged from our analysis as particularly underexplored and that yet would bridge the analytical and policy added value of this work is the role of demand in its various facets. Demand links structural change and inclusion: the income distribution that ensues from structural change might (or indeed might not) support the effective demand by more diffuse groups for novel products or services, which might (or might not) then lead to better social and economic outcomes, in either a vicious or a virtuous circle. The political economy of value creation and redistribution as a result of structural change is therefore of crucial importance to ensure that innovation capacity is made sustainable in the long run to redirect pathways of innovation toward inclusive structural change.

Third, and relatedly, is the importance of identifying needs, those that are recognized by local communities themselves but also those that are not. This goes beyond the creation of effective demand in a Keynesian perspective: creation of demand might not necessarily work toward satisfying needs. It may include, for example, accountability mechanisms through which needs are made known to policymakers. However, fourthly, the role of public procurement emerged as a fundamental element in any political economy strategy of structural change. This goes hand-in-hand with our initial reflection on the role of the government in identifying areas of technological opportunities.

\subsubsection{Measurement and Indicators}


Last but certainly not least, the importance of measurement and the development of appropriate indicators that are able to capture all the dimensions in our framework emerged strongly from both our analysis and our interactions with academics, policymakers and other stakeholders (Gault, 2018).

Ideally, a radically new approach to measurement would entail including questions in surveys, which would allow us to capture the value upgrading and the degree of inclusivity of an innovation, for instance, by including a question on innovation in Labour Force Surveys or in the Census. This has not yet been considered in relevant statistical offices. From the perspective of research and policy learning, devising properly designed mixed methods that bridge data analysis and case studies is a top priority. To move toward this direction, smaller scale surveys rather than larger ones may at times be more focused, less resource intensive and more effective and informative when researchers and policymakers need to tackle the complexity of issues outlined in this paper. 


\section{References}

Acemoglu, D. and J. Robinson. 2012. Why Nations Fail: The Origins of Power, Prosperity, and Poverty. London: Profile Books.

Acemoglu, D., S. Johnson, and J.A. Robinson. 2005. "Institutions as a Fundamental Cause of Long-Run Growth.” In Handbook of economic growth, edited by P. Aghion and S.N. Durlauf. Amsterdam: Elsevier.

Aghion, P., U. Akcigit, A. Bergeaud, R. Blundell, and D. Hemous. 2015. "Innovation and Top Income Inequality." NBER working paper, No. 21247. Cambridge, MA: The National Bureau of Economic Research.

Aghion, P., U. Akcigit, A. Bergeaud, R. Blundell, and D. Hemous. 2019. "Innovation and Top Income Inequality." Review of economic studies, 86(1), 1-45.

Aghion, P., U. Akcigit, A. Hyytinen, and O. Toivanen. 2017. "The Origins of Inventors.” NBER working paper, No. 24110. Cambridge, MA: The National Bureau of Economic Research.

Agyapong, F.O., A. Agyapong, and K. Poku. 2017. "Nexus Between Social Capital and Performance of Micro and Small Firms in an Emerging Economy: The Mediating Role of Innovation.” Cogent business \& management, 4(1), 1309784.

Akhtar, S., H. Hahmv, and S.F. Stone. 2018. Harnessing science, technology and innovation for inclusive and sustainable development in Asia and the Pacific. United Nations Economic and Social Commission for Asia and the Pacific, Bangkok.

Alesina, A. and R. Perotti. 1996. "Income distribution, Political Instability, and Investment." European economic review, 40(6), 1203-1228. 
Altenburg, T. 2009. “Building Inclusive Innovation Systems in Developing Countries:

Challenges for IS Research.” In Handbook of innovation systems and developing countries, edited by R-A Lundvall, K.J. Joseph, C. Chaminade, and J. Vang. Cheltenham: Edward Elgar.

Amighini, A. and M. Sanfilippo. 2014. "Impact of South-South FDI and Trade on the Export Upgrading of African Economies." World development, 64, 1-17.

Anand, R., M. Saurabh, and S.J. Peiris. 2013. "Inclusive Growth: Measurement and Determinants." IMF working paper, No. 13/135. Washington DC: International Monetary Fund.

Arza, V. and P. van Zwanenberg. 2014. "Innovation in Informal Settings but in Which Direction? The Case of Small Cotton Farming Systems in Argentina." Innovation and development, 4(1), 55-72.

Atkinson, A.B. and F. Bourguignon. 1999. "Poverty and Inclusion from a World Perspective." Paper prepared for ABCDE Europe conference, Paris, France.

Autor, D., D. Dorn, L. Katz, C. Patterson, and J. Van Reenen. 2017. "The Fall of the Labor Share and the Rise of Superstar Firms.” NBER Working Paper, No. 23396. Cambridge, MA: The National Bureau of Economic Research.

Banerjee, A.V and A.F. Newman. 1993. "Occupational Choice and the Process of Development." The journal of political economy, 101(2), 274-298.

Barrientos, S., G. Gereffi, and A. Rossi. 2011. "Economic and Social Upgrading in Global Production Networks: A New Paradigm for a Changing World.” International labour review, 150(3-4), 319-340. 
Barrientos, S., P. Knorringa, B. Evers, M. Visser, and M. Opondo. 2016a. "Shifting Regional Dynamics of Global Value Chains: Implications for Economic and Social Upgrading in African Horticulture." Environment and planning a: Economy and space, $48(7), 1266-1283$.

Barrientos, S., G. Gereffi, and J. Pickles. 2016b. "New Dynamics of Upgrading in Global Value Chains: Shifting Terrain for Suppliers and Workers in the Global South.” Environment and planning a: Economy and space, 48(7), 1214-1219.

Bell, A., R. Chetty, X. Jaravel, N. Petkova, and J. Van Reenen. 2016. “The Lifecycle of Inventors." SSRN electronic journal [online]. Available at: https://scholar.harvard.edu/sites/scholar.harvard.edu/files/xavier/files/inventors.pdf (Accessed: 12 August 2020)

Bell, M. 2007. Technological learning and the development of production and innovative capacities in the industry and infrastructure sectors of the least developed countries: What role for ODA?. Background paper No. 10 for the least developed countries report, United Nations Conference on Trade and Development, Geneva. Bell, M. 2009. "Innovation Capabilities and Directions of Development.” STEPS working paper, 33. Brighton: STEPS Centre.

Bernhardt, T. and R. Pollak. 2016. "Economic and Social Upgrading Dynamics in Global Manufacturing Value Chains: A Comparative Analysis." Environment and planning a: Economy and space, 48(7), 1220-1243.

Bourguignon, F. 2003. "The Growth Elasticity of Poverty Reduction: Explaining Heterogeneity Across Countries and Time Periods." In Inequality and growth: Theory and policy implications, edited by T.S. Eicher and S.J. Turnovsky. Cambridge, MA: MIT Press. 
Bradley, S.W., J.S McMullen, K. Artz, and E.M. Simiyu. 2012. "Capital is Not Enough: Innovation in Developing Economies." Journal of management studies, 49(4), 684-717.

Brewer, B.D. 2011. "Global Commodity Chains \& World Income Inequalities: The Missing Link of Inequality and the "Upgrading" Paradox." Journal of world-systems research, 17(2), 308-327.

Chataway, J., R. Hanlin, and R. Kaplinsky. 2014. "Inclusive Innovation: An Architecture for Policy Development." Innovation and development, 4(1), 33-54.

Cimoli, M. and G. Dosi. 1995. "Technological Paradigms, Patterns of Learning and Development: An Introductory Roadmap.” Journal of evolutionary economics, 5, $243-268$.

Cimoli, M. and G. Porcile. 2009. "Sources of Learning Paths and Technological Capabilities: An Introductory Roadmap of Development Processes.” Economics of innovation and new technology, 18(7), 675-694.

Cimoli, M. and G. Porcile. 2011. "Learning, Technological Capabilities, and Structural Dynamics.” In The Oxford handbook of Latin American economics, edited by J.A. Ocampo and J. Ros. Oxford: Oxford University Press.

Cirera, X., and W.F. Maloney. 2017. The innovation paradox: Developing-country capabilities and the unrealized promise of technological catch-up. Washington DC: The World Bank.

Cohen, W.M. and D.A. Levinthal. 1989. "Innovation and Learning: The Two Faces of R \& D." The economic journal, 99(397), 569-596. 
Cozzens, S. and J. Sutz. 2014. "Innovation in Informal Settings: Reflections and Proposals for a Research Agenda." Innovation and development, 4(1), 5-31.

Cumbers, A. and D. MacKinnon. 2004. "Introduction: Clusters in Urban and Regional Development." Urban studies, 41(5-6), 959-969.

Demir, F. and O.S. Dahi. 2011. "Asymmetric Effects of Financial Development on South-South and South-North Trade: Panel Data Evidence from Emerging Markets." Journal of development economics, 94(1), 139-149.

Di Meglio, G., J. Gallego, A. Maroto, and M. Savona. 2018. "Services in Developing Economies. The Deindustrialization Debate in Perspective.” Development and change, 49(6), 1495-1525.

Didier, L. 2017. "South-South Trade and Geographical Diversification of Intra-SSA Trade: Evidence from BRICs: South-South Trade.” African development review, 29(2), 139-154.

Dolan, C. and J. Humphrey. 2000. "Governance and Trade in Fresh Vegetables: The Impact of UK Supermarkets on the African Horticulture Industry.” The journal of development studies, 37(2), 147-176.

Duranton, G. and D. Puga. 2004. "Microfoundations of Urban Agglomeration Economies." In Handbook of regional and urban economics, edited by G. Duranton, J.V. Henderson, and W.C. Strange. 4th ed. Amsterdam: Elsevier.

Esteban, J. and D. Ray. 2011. "Linking Conflict to Inequality and Polarization." American economic review, 101(4), 1345-1374. 
Farole, T., A. Rodríguez-Pose, and M. Storper. 2011. "Human Geography and the Institutions that Underlie Economic Growth.” Progress in human geography, 35(1), $58-80$.

Foster, C. and R. Heeks. 2013. “Conceptualising Inclusive Innovation: Modifying Systems of Innovation Frameworks to Understand Diffusion of New Technology to Low-Income Consumers." The European journal of development research, 25(3), $333-355$.

Fressoli, M., E. Arond, D. Abrol, A. Smith, A. Ely, and R. Dias. 2014. "When Grassroots Innovation Movements Encounter Mainstream Institutions: Implications for Models of Inclusive Innovation." Innovation and development, 4(2), 277-292.

Fu, X., P. Mohnen, and G. Zanello. 2018. "Innovation and Productivity in Formal and Informal Firms in Ghana." Technological forecasting and social change, 131(June), $315-325$.

Galvez-Nogales, E. 2010. Agro-based clusters in developing countries: Staying competitive in a globalized economy. Food and Agriculture Organization of the United Nations, Rome.

Gault, F. 2018. "Defining and Measuring Innovation in All Sectors of the Economy." Research policy, 47(3), 617-622.

Gold, R., H. Görg, A. Hanley, and A. Seric. 2017. "South-South FDI: Is It Really Different?.” Review of world economics, 153(4), 657-673.

Hanlin, R. and R. Kaplinsky. 2016. "South-South Trade in Capital Goods - The Market-Driven Diffusion of Appropriate Technology." European journal of development research, 28, 361-378. 
Hausmann, R. and D. Rodrik. 2003. "Economic Development as Self-Discovery." Journal of development economics, 72, 603-633.

Heeks, R., C. Foster, and Y. Nugroho. 2014. "New Models of Inclusive Innovation for Development." Innovation and development, 4(2), 175-185.

Hickey, S., K. Sen, and B. Bukenya (eds.). 2014. The Politics of Inclusive

Development: Interrogating the Evidence. Oxford: Oxford University Press.

Hidalgo, C.A., B. Klinger, A.-L. Barabasi, and R. Hausmann. 2007. "The Product Space Conditions the Development of Nations." Science, 317(5837), 482-487.

Hossain, M. 2016. “Grassroots Innovation: A Systematic Review of Two Decades of Research.” Journal of cleaner production, 137(November), 973-981.

Jaffee, S. and O. Masakure. 2005. "Strategic Use of Private Standards to Enhance International Competitiveness: Vegetable Exports from Kenya and Elsewhere.” Food policy, 30, 316-333.

Jha, S. and P. McCawley. 2011. "South-South Economic Linkages: An Overview." ADB economics working paper series, 270. Manila: Asian Development Bank.

Kaplinksy, R. 2000. "Spreading the Gains from Globalization: What Can Be Learned from Value Chain Analysis?.” IDS working paper, 100. Brighton: Institute of Development Studies.

Kaplinsky, R. 2011. “Schumacher Meets Schumpeter: Appropriate Technology Below the Radar." Research policy, 40(2), 193-203.

Kaplinsky, R. 2018. "Fostering Inclusive Innovation for Sustainable Development." SPRU and IDS background Paper, 9. Brighton: Science Policy Research Unit and Institute of Development Studies. 
Keller, W. 1996. “Absorptive Capacity: On the Creation and Acquisition of Technology in Development." Journal of development economics, 49(1), 199-227.

Kraemer-Mbula, E. and S. Wunsch-Vincent. 2016. The Informal Economy in Developing Nations: Hidden Engine of Innovation?. Cambridge: Cambridge University Press.

Kuznets, S. 1973. "Modern Economic Growth: Findings and Reflections." The American economic review, 63(3), 247-258.

Leach, M., I. Scoones, and A. Stirling. 2007. "Pathways to Sustainability: An Overview of the STEPS Centre Approach.” STEPS Approach Paper. Brighton: STEPS Centre.

Lee, N. 2011. “Are Innovative Regions more Unequal? Evidence from Europe.” Environment and planning c: Government and policy, 29(1), 2-23.

Lee, J. and G. Gereffi. 2015. "Global Value Chains, Rising Power Firms and Economic and Social Upgrading.” Critical perspectives on international business, 11(3/4), 319-339.

Lopez Gonzalez, J., V. Meliciani, M. Savona. 2019. “When Linder Meets Hirschman. Inter-Industry Linkages and Global Value Chains in Business Services.” Industrial and corporate change, 28(6), 1555-1586.

Lundvall, B. 2007. "National Innovation Systems-Analytical Concept and Development Tool.” Industry \& innovation, 14(1), 95-119.

Maertens, M. and J. Swinnen. 2009. “Trade, Standards, and Poverty: Evidence from Senegal." World development, 37(1), 161-178. 
Marquez, P., T. Ciarli, and M. Savona. 2017. Technology Transfer and Inclusive Structural Change for Development. A Review of the Evidence. Brighton: Science Policy Research Unit and Institute of Development Studies.

Martin, R. and P. Sunley. 2003. "Deconstructing Clusters: Chaotic Concept or Policy Panacea?." Journal of economic geography, 3(1), 5-35.

McGranahan, G., E. Kasper, and M. Maestre. 2017. Market systems development in the cities of rapidly urbanising countries. London: The BEAM Exchange.

McMillan, M., D. Rodrik, and I. Verduzco-Gallo. 2014. "Globalization, Structural Change, and Productivity Growth, with an Update on Africa." World development, $63,11-32$.

Meliciani, V. and M. Savona. 2015. "The Determinants of Regional Specialisation in Business Services: Agglomeration Economies, Vertical Linkages and Innovation.” Journal of economic geography, 15, 387-416.

Milberg, W. and D. Winkler. 2011. "Economic and Social Upgrading in Global Production Networks: Problems of Theory and Measurement." International labour review, 150(3-4), 341-365.

Mohanty, S.K., L. Franssen, and S. Saha. 2019. The power of international value chains in the global south. Geneva: International Trade Centre.

OECD. 2015. Innovation policies for inclusive development. Scaling up inclusive innovations. Paris: Organisation for Economic Co-operation and Development.

OECD/Eurostat. 2018. Oslo Manual 2018: Guidelines for Collecting, Reporting and Using Data on Innovation. 4th ed. Paris: Eurostat and Luxembourg: OECD Publishing. 
Papaioannou, T. 2014. "Innovation and Development in Search of a Political Theory of Justice.” International journal of technology and globalisation, 7(3), 179-202.

Paunov, C. 2013. "Innovation and Inclusive Development: A Discussion of the Main Policy Issues." STI working paper, 2013/1. Paris: Organisation for Economic Cooperation and Development.

Pietrobelli, C. and R. Rabellotti. 2011. "Global Value Chains Meet Innovation Systems: Are There Learning Opportunities for Developing Countries?.” World development, 39(7), 1261-1269.

Planes-Satorra, S. and C. Paunov. 2017. "Inclusive Innovation Policies." OECD science, technology and industry working papers, 2017/02. Paris: OECD Publishing. Ponte, S. and P. Gibbon. 2005. "Quality Standards, Conventions and the Governance of Global Value Chains.” Economy and society, 34(1), 1-31.

Porter, M. 1998. "Clusters and the New Economic Competition." Harvard business review, 76(6), 77-90.

Poulton, C., G. Tyler, P. Hazell, A. Dorward, J. Kydd, and M. Stockbridge. 2008. AllAfrica review of experiences with commercial agriculture: Lessons from success and failure. Background report for the World Bank project "Competitive commercial agriculture in sub-saharan Africa”, SOAS, University of London, London.

Ravallion, M. 2004. "Pro-Poor Growth: A Primer.” World bank policy research working paper, No. 3242. Washington DC: World Bank.

Ravallion, M. and S. Chen. 2003. "Measuring Pro-poor Growth." Economic letters, 78(1), 93-99. 
Robson, P.J.A., H.M. Haugh, and B.A. Obeng. 2009. "Entrepreneurship and Innovation in Ghana: Enterprising Africa.” Small Business Economics, 32, 331-350.

Rodrik, D. 2005. “Growth Strategies.” In Handbook of economic growth, edited by P. Aghion and S.N. Durlauf. 1st ed. Amsterdam: Elsevier.

Saha, A. and T. Ciarli. 2018. "Innovation, Structural Change and Inclusion: A Cross Country PVAR Analysis.” SPRU working paper series, 1/2018. Brighton: Science Policy Research Unit.

Saha, A., J. Thorpe, and S. Ayele. 2018. "Case Studies on Innovations in Breeding Practices in Kenya and Anti-retroviral Therapy Service Provision in Mozambique.” IDS working paper, 505. Brighton: Institute of Development Studies.

Schmitz, H. 1999. "Collective Efficiency and Increasing Returns.” Cambridge journal of economics, 23, 465-483.

Schumpeter, J.A. 1934. The Theory of Economic Development: An Inquiry into Profits, Capital, Credit, Interest, and the Business Cycle. Cambridge, MA: Harvard University Press.

Schumpeter, J.A. 1942. Capitalism, Socialism and Democracy. London: Allan and Unwin.

Scott, A.J. and M. Storper. 2015. "The Nature of Cities: The Scope and Limits of Urban Theory." International journal of urban and regional research, 39(1), 1-15.

Smith, A., M. Fressoli, and H. Thomas. 2014. "Grassroots Innovation Movements: Challenges and Contributions." Journal of cleaner production, 63, 114-124. 
Srinivas, S. 2014. "Demand and Innovation: Paths to Inclusive Development." In Innovation in India: Combining economic growth with inclusive development, edited by S.V. Ramani. Cambridge: Cambridge University Press.

Storper, M. and A.J. Scott. 2016. "Current Debates in Urban Theory: A Critical Assessment." Urban studies, 53(6), 1114-1136.

Syrquin, M. 1988. "Patterns of Structural Change.” In Handbook of development economics, edited by H.B. Chenery and T.N. Srinivasan. Amsterdam: Elsevier.

Teichman, J.A. 2016. The Politics of Inclusive Development: Policy, State Capacity, and Coalition Building. London: Palgrave Macmillan.

Timmer, C.P. 2009. A World Without Agriculture: The Structural Transformation in Historical Perspective. Washington DC: American Enterprise Institute Press.

Tokatli, N. 2013. "Toward a Better Understanding of the Apparel Industry: A Critique of the Upgrading Literature.” Journal of economic geography, 13(6), 993-1011.

Van Biesebroeck, J. 2005. "Firm Size Matters: Growth and Productivity Growth in African Manufacturing." Economic development and cultural change, 53(3), 545583.

Verspagen, B. 2004. "Structural Change and Technology. A Long View." Revue économique, 55(6), 1099-1126.

Wolman, H. and Hincapie, D. 2014. "Clusters and Cluster-based Development Policies." Economic development quarterly, 29(2), 135-149.

World Bank. 2006. World development report (WDR) 2006: Equity and development. Washington DC: The World Bank. 
Zanello, G., X. Fu, P. Mohnen, and M. Ventresca. 2015. "The Creation and Diffusion of Innovation in Developing Countries: A Systematic Literature Review." Journal of economic surveys, 30(5), 884-912.

Zeschky, M., B. Widenmayer, B., and O. Gassmann. 2011. "Frugal Innovation in Emerging Markets.” Research-technology management, 54(4), 38-45. 
Figure 1.1 The Main Variables and Relationship

Source: Authors' own

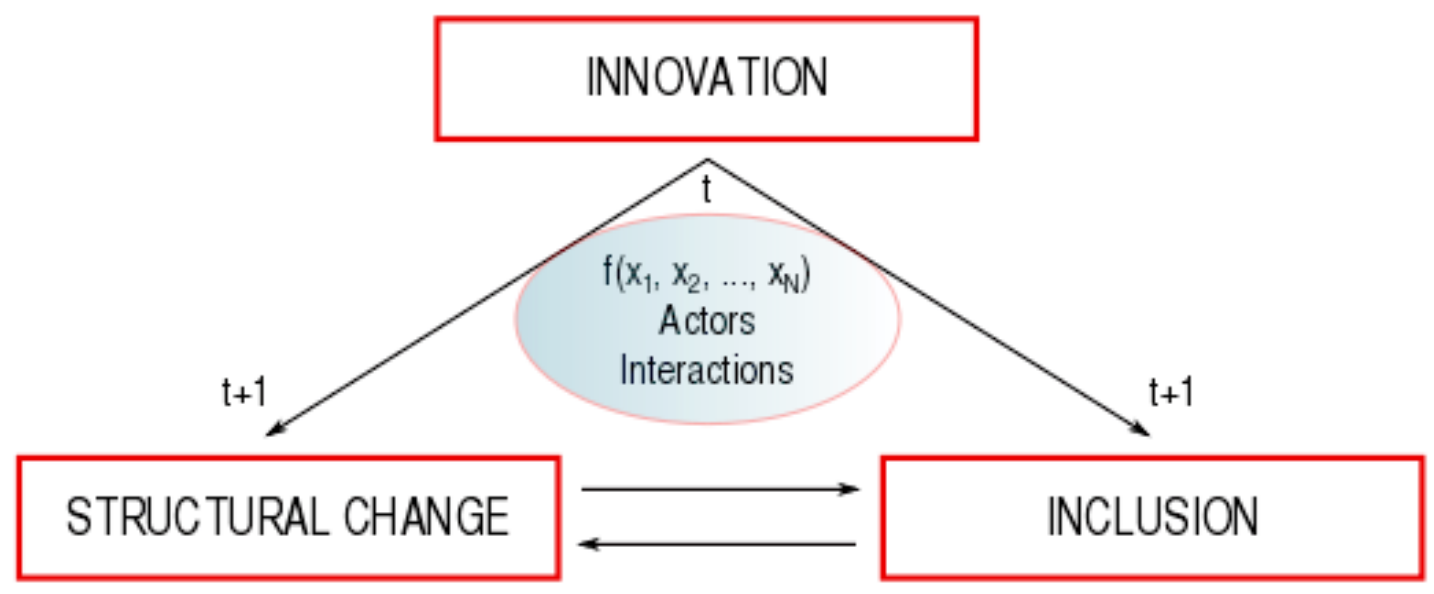


Figure 3.1 Dynamic Relations between Innovation, Structural Changes, and Inclusion

Source: Authors' own elaboration

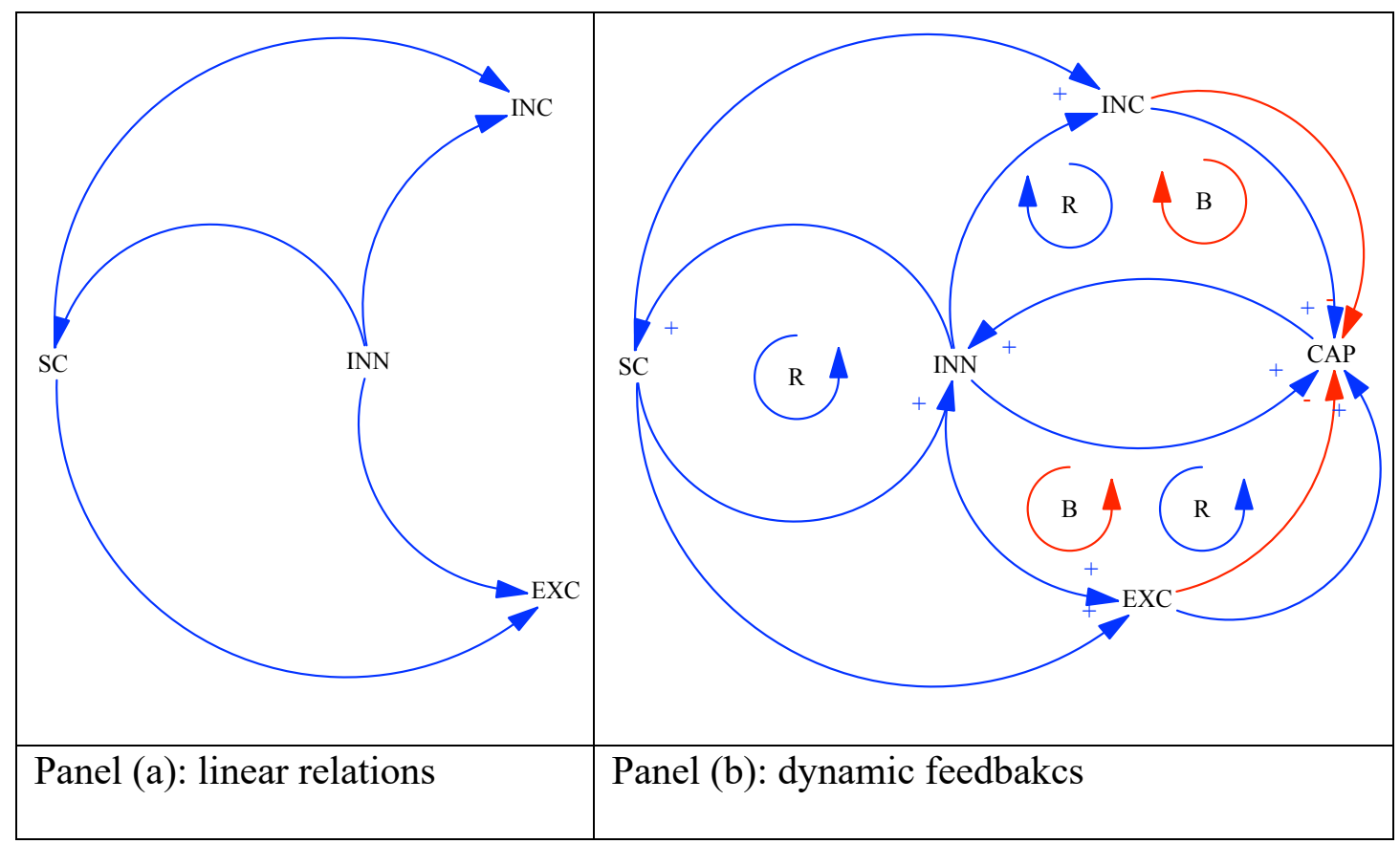

Notes: INN: innovation; SC: structural changes; INC: inclusion; EXC: exclusion; CAP: capabilities; R: reinforcing mechanisms; B: balancing mechanisms. Blue indicates a positive relation; red indicates a negative relation. 
Source: Authors' own elaboration

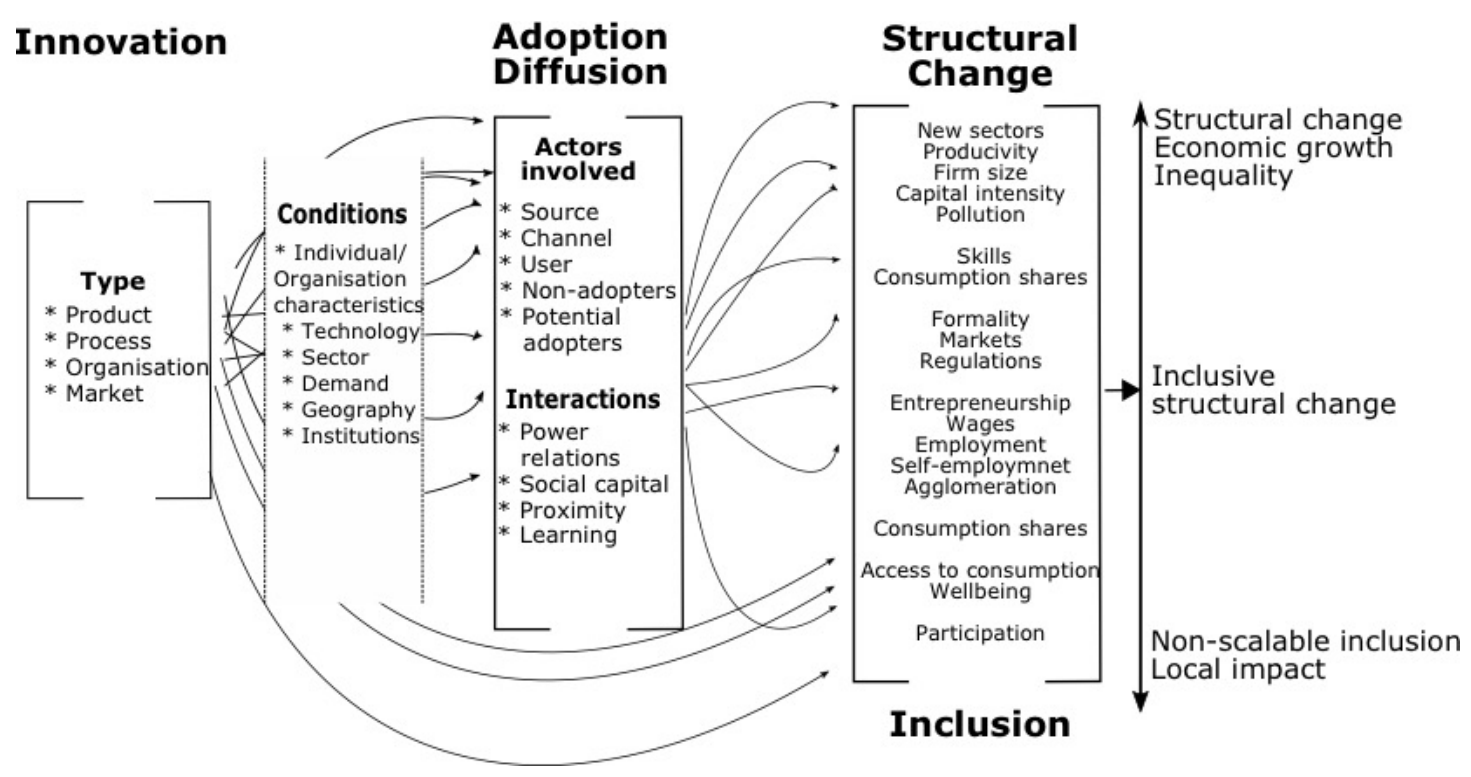

Notes: Arrows represent pathways. The variables that represent conditions, actors and interactions define the effect of innovation on adoption/diffusion, and on structural change and inclusion outcomes. Some pathways go through adoption/diffusion, while some variables have a direct impact on structural change and inclusion. Variables represent the innovation channels and sources, the type of innovation, as well as meso- and macro-conditions such as sectors, demand, geography, and institutions. In the extremes, innovation may have a positive effect on structural change, and a negative effect on inclusion (top end of the right axis), or no or negative effect on structural change and a positive effect on inclusion (bottom end of the left axis). The axis measures the trade-offs between structural change and inclusion outcomes. Structural change and inclusion are therefore not intended to represent different options - they are not mutually exclusive - but rather innovation processes may lead to different degrees of inclusive structural change. 